\title{
NS Contemporary concepts of pain surgery
}

\author{
JNSPG 75th Anniversary Invited Review Article
}

Kim J. Burchiel, MD, and Ahmed M. Raslan, MD

Department of Neurological Surgery, Oregon Health \& Science University, Portland, Oregon

Pain surgery is one of the historic foundations of neurological surgery. The authors present a review of contemporary concepts in surgical pain management, with reference to past successes and failures, what has been learned as a subspecialty over the past 50 years, as well as a vision for current and future practice. This subspecialty confronts problems of cancer pain, nociceptive pain, and neuropathic pain. For noncancer pain, ablative procedures such as dorsal root entry zone lesions and rhizolysis for trigeminal neuralgia (TN) should continue to be practiced. Other procedures, such as medial thalamotomy, have not been proven effective and require continued study. Dorsal rhizotomy, dorsal root ganglionectomy, and neurotomy should probably be abandoned. For cancer pain, cordotomy is an important and underutilized method for pain control. Intrathecal opiate administration via an implantable system remains an important option for cancer pain management. While there are encouraging results in small case series, cingulotomy, hypophysectomy, and mesencephalotomy deserve further detailed analysis. Electrical neuromodulation is a rapidly changing discipline, and new methods such as high-frequency spinal cord stimulation (SCS), burst SCS, and dorsal root ganglion stimulation may or may not prove to be more effective than conventional SCS. Despite a history of failure, deep brain stimulation for pain may yet prove to be an effective therapy for specific pain conditions. Peripheral nerve stimulation for conditions such as occipital neuralgia and trigeminal neuropathic pain remains an option, although the quality of outcomes data is a challenge to these applications. Based on the evidence, motor cortex stimulation should be abandoned. TN is a mainstay of the surgical treatment of pain, particularly as new evidence and insights into TN emerge. Pain surgery will continue to build on this heritage, and restorative procedures will likely find a role in the armamentarium. The challenge for the future will be to acquire higher-level evidence to support the practice of surgical pain management.

https://thejns.org/doi/abs/10.3171/2019.1.JNS181620

KEYWORDS pain; ablative surgery; neuromodulation; trigeminal neuralgia

$\mathrm{T}$ HE past 50 years have produced a litany of advances in the field of pain surgery. Our goal in this review is to highlight the successes and failures of this period, and to project our expectations for future innovation and improvement in this subspecialty of neurosurgery.

In its most classical definition, pain is the organism's sensation of tissue injury, or impending tissue injury. Of course, pain as experienced by our patients is a complex biopsychosocial phenomenon. Recognizing that this subject is far more complex than this brief review will allow, this paper will not attempt to delve into the complexity of pain from the standpoints of psychological predispositions or consequences, social implications, or disability. Rather, we will focus on the current practice of pain surgery, primarily in the specialty of neurological surgery, its past, present, and projected future.

Chronic pain has been defined as any pain persisting for more than 6 months. With this as a starting point, pain can be further characterized as nociceptive, neuropathic, or cancer-related. The surgical treatment of trigeminal neuralgia $(\mathrm{TN})$ occupies a special place in the pain surgery armamentarium, and will be addressed separately.

Nociceptive pain involves activation of peripheral pain receptors, A-delta and $\mathrm{C}$ fibers. Neuropathic pain is a distortion of pain signaling or the nervous system's processing of sensory input, including segmental (spinal

ABBREVIATIONS CRPS = complex regional pain syndrome; $\mathrm{DBS}=$ deep brain stimulation; $\mathrm{DREZ}=$ dorsal root entry zone; $\mathrm{DRG}=$ dorsal root ganglion; $\mathrm{DRGectomy} \mathrm{=}$ dorsal root ganglionectomy; DRGS = DRG stimulation; $\mathrm{MCS}=$ motor cortex stimulation; NVC = neurovascular compression; ONS = occipital nerve stimulation; PAG = periaqueductal gray; PNS = peripheral nerve stimulation; PVG = periventricular gray; RF = radiofrequency; $\mathrm{SCS}$ = spinal cord stimulation; $\mathrm{SRS}=$ stereotactic radiosurgery; TN $=$ trigeminal neuralgia; $T N P=$ trigeminal neuropathic pain.

SUBMITTED January 1, 2019. ACCEPTED January 3, 2019.

INCLUDE WHEN CITING DOI: 10.3171/2019.1.JNS181620. 
cord) or suprasegmental (brainstem, subcortical, cortical) misrepresentation of pain in the absence of a nociceptive peripheral stimulus. In fact, much neuropathic pain is the consequence of loss of peripheral input, or more properly, deafferentation pain. Thus, neuropathic pain is typically derived from some type of injury to the peripheral or central nervous system. Cancer pain is related to the progression of a malignancy, with both tissue injury and damage to the nervous system, which can produce both nociceptive and neuropathic pains.

The surgical treatment of pain falls roughly into two types: ablative, or more properly destructive procedures, and neuromodulation. These two approaches to pain surgery will be discussed in some detail. The surgical treatment of TN incorporates principles of both ablative and nonablative surgery.

Destructive procedures for pain control represent the beginnings of pain surgery, and represent some of the most established and traditional procedures in the specialty of neurological surgery. Over the course of the last 50 years, the practice of destructive procedures has given way to the concept of neuromodulation; ${ }^{22,93}$ that is, procedures that were usually both testable and reversible, and that took advantage of the neurophysiology of the pain detection and reaction systems, manipulating both electrical and neurochemical signaling.

Space does not allow a comprehensive discussion of nonsurgical pain therapy. However, it is worth noting that while medical therapy, primarily using strong opiates, for nociceptive pain is often initially very effective, no specific or highly effective drugs exist for the treatment of neuropathic pain. The medical treatment of neuropathic pains has been dominated by the use of "borrowed" drugs, such as anticonvulsants and antidepressants, which mitigated neuropathic pain at the expense of significant side effects. Thus, surgical treatment of pain is very often targeted at pains of neuropathic origin.

We will address the current state of surgical pain management in two sections: ablative surgery and neuromodulation. Ablative surgery will be further divided into three topics: noncancer pain, TN, and cancer-related pain. Our neuromodulation discussion will deal predominantly with neuropathic pain.

\section{Ablative Surgery \\ Noncancer Pain}

Ablative, or more properly destructive, procedures for noncancer (i.e., nonmalignant) pain represent the foundation for much of pain surgery. The litany of these procedures includes cingulotomy, thalamotomy, hypophysectomy, mesencephalotomy, tractotomy, cordotomy, dorsal root entry zone (DREZ) lesions, midline myelotomy, dorsal rhizotomy, ganglionectomy, sympathectomy, and neurotomy. We will subsequently discuss the case for cordotomy for cancer pain later in this review. However, with few exceptions, the literature on these ablative procedures is limited to class III cases series. Somewhat higher quality evidence does exist supporting radiofrequency (RF) rhizotomies for different pain origins, including lumbar facet syndrome, cervical facet pain, and type 1 (classical) TN.
Despite a long history of use in neurosurgery, the evidence supporting destructive procedures for "benign" pain conditions remains very limited. ${ }^{16}$

\section{Medial Thalamotomy}

The evidence for medial thalamotomy remains class III, and it is not a common procedure in pain surgery practice. Despite this, some centers continue to publish case series that appear to show some patient benefit. ${ }^{47}$

Roberts and Pouratian have done a systematic review of the role of SRS for the treatment of chronic intractable pain, and concluded that both thalamic and pituitary SRS may be effective for select patients with chronic pain, although most studies reviewed did not fulfill modern evidentiary requirements, and were completed before neuromodulatory and intrathecal therapies came into common use. $^{97}$

Menon $^{74}$ has likewise recently provided a historical review of intracranial ablative procedures for the treatment of chronic pain, including thalamotomy, mesencephalic tractotomy (mesencephalotomy), and anterior cingulotomy, and concluded that continued clinical investigation was necessary.

\section{DREZ Lesions}

In his original descriptions of DREZ lesions for neuropathic pain, Sindou discovered what is arguably one of the most important procedures in pain surgery. ${ }^{101}$ The results of DREZ lesions, particularly for pain related to brachial and lumbosacral plexus avulsion, have withstood the test of time as an effective ablative procedure for pain control. In most cases of neuropathic pain, the putative pain generator is unknown, and may, in fact, represent a system change in the segmental and suprasegmental matrix that produces pain perception invoking action, emotion, and memory. In the case of plexus avulsion, the generator appears to be in the region of the nucleus proprius (lamina IV-V) of the dorsal horn, the locus of so-called "wide dynamic range" neurons that signal both nonpainful and painful input to the CNS and appear to become hyperactive after root avulsion. Dorsal nerve root avulsions take with them the superficial layers of the spinal cord, including Lissauer's tract, lamina I (marginal), and layers II-III (substantia gelatinosa), which damages the input of both the enkephalinergic and other inhibitory circuitry and their influences on deeper layers of the dorsal horn. Ablation of the nucleus proprius as a consequence of the DREZ procedure produces effective and durable pain relief. ${ }^{29}$ Long-term outcome with DREZ lesions can also be correlated with preoperative MRI. ${ }^{59}$ Trigeminal nucleus caudalis DREZ operations may also be effective in the treatment of intractable facial pain syndromes related to deafferentation. ${ }^{49}$

\section{Dorsal Rhizotomy}

Since the seminal paper by Loeser, ${ }^{67}$ little further meaningful publication has occurred in the neurosurgical literature on dorsal rhizotomy for pain control. What current literature that does exist on this topic derives from the effects of selective dorsal rhizotomy for spasticity and the pain control that can be achieved in addition to the prin- 
cipal improvements on tone and mobility after this procedure. ${ }^{19,81,82,108}$ There is little contemporary evidence that would support dorsal rhizotomy as a means to produce relief of chronic pain, and its use for this indication has virtually disappeared.

\section{Dorsal Root Ganglionectomy}

Theoretically, dorsal root ganglionectomy (DRGectomy) should have an advantage over neurotomy because the primary afferent cell bodies are removed, thus preventing peripheral sensory axonal regeneration, eliminating ventral root afferents with cell somata in the dorsal root ganglion (DRG) ${ }^{18}$ and spontaneous nociceptive activity from the DRG cell bodies themselves. ${ }^{14,117}$ Although early studies highlighted lumbar DRGectomy for failed back surgery syndrome, ${ }^{107} 5$-year follow-up results were disappointing. ${ }^{78}$ Results in the thoracic region have also shown a tendency to pain recurrence, even in dermatomes that were not involved initially.119

Most recently DRGectomy has focused on occipital neuralgia, extirpating the C2 and C3 DRG. However, careful survival analysis (Kaplan-Meier) of the results reveals a slow decline in pain relief from the time of surgery over several years. ${ }^{1}$ More recent data have largely ratified these conclusions, with steady recurrence of pain through 2 years of follow-up, ${ }^{83}$ with neuromodulation being a better initial option in occipital neuralgia. ${ }^{54}$

A recent systematic review of current DRG therapeutics, including DRGectomy, concluded that only poor evidence exists regarding current therapeutic techniques, but that neuromodulatory or pharmacological strategies were "on the horizon." Again, the authors concluded that more prospective studies are required. ${ }^{85}$

\section{Neurotomy and Neuroma Excision}

The techniques for neurotomy, neurolysis, and neurectomy have been described in the neurosurgical canon. ${ }^{65}$ In fact, the published literature is rife with case series of neurolytic procedures directed at a multiplicity of disorders, in many surgical subspecialties. If the number of published studies is any indication, neurosurgical interest in this field is rather low. ${ }^{15}$ Overall, systematic reviews of prospective studies with defined treatment protocols on the topic are relatively rare. It would be difficult to do justice to this literature within the scope of the current review, but several studies can serve as exemplars, both of $\mathrm{RF}$ and surgical neurotomy.

In one recent review of the therapeutic effectiveness of cervical facet joint interventions, the authors concluded that the evidence for cervical RF neurotomy is only fair. ${ }^{32}$ A meta-analysis of randomized controlled trials concluded that conventional RF denervation of the lumbar facets resulted in significant 12-month reductions in low-back pain in patients showing the best response to diagnostic nerve block when compared with sham procedures or epidural nerve blocks. Although the results were statistically significant, the lower end of the pain scores for the treatment group encompassed the minimal clinically important difference, indicating that the pain relief was modest, even over this relatively short follow-up period. ${ }^{62} \mathrm{~A}$ critical review of the American Pain Society's clinical practice guidelines for interventional techniques found only fair support for neurotomy for pain relief. For RF neurotomy, 4 of the 5 studies that met their criteria were positive for short-term relief whereas for long-term relief only 1 of 2 studies was shown to be positive. ${ }^{70} \mathrm{~A}$ more recent review found somewhat more favorable results, although followup criteria were limited to 1 year. ${ }^{30}$

Surgical neurotomy for pain relief continues to be reported in specialty journals, mostly in retrospective, single-center experiences. For example, the efficacy of retroperitoneal "triple neurectomy" for refractory neuropathic inguinodynia has been reported effective "with durable efficacy" from 90 days to 3 years. Although the outcome of this study was favorable, the follow-up was selective, and not well documented by contemporary standards. ${ }^{76}$ Retrospective neurosurgical studies of this problem have shown modest long-term benefit for ilioinguinal and genitofemoral neurectomy for postherniorrhaphy chronic pain. ${ }^{123}$ Excision of neuromas can improve patient-reported pain, depression, and quality of life, ${ }^{26}$ although some authors have indicated that simple neuroma excision has the highest incidence of recurrent pain, compared to other peripheral nerve surgical techniques. ${ }^{38}$

\section{Cancer Pain}

Considering that approximately one-third of patients with end-stage cancer have medically intractable pain, and fear of pain exceeds fear of death in many cancer patients, surgical management of cancer pain should be a high priority.$^{90}$ Procedures are available to help these patients, and at least in the case of cordotomy, the current evidence would favor a greater role for neurosurgery in these patients.

\section{Cingulotomy/Pulvinotomy}

Viswanathan et al. ${ }^{116}$ has recently reviewed cingulotomy for medically refractory cancer pain and concluded that for patients with cancer pain with diffuse pain syndromes, head and neck malignancies, and significant emotional distress, cingulotomy may be a safe treatment option with minimal cognitive changes.

\section{Hypophysectomy}

With the advent of neuromodulatory approaches to pain, particularly intrathecal opiate administration, the use of hypophysectomy for control of cancer pain has largely fallen out of favor. Despite this, prior reviews of surgical and chemical hypophysectomy have shown comparable results, ranging from $70 \%$ to $75 \%$ successful pain reduction. The mechanism or mechanisms by which hypophysectomy produces relief from cancer pain have yet to be elucidated, and does not appear to be related to postradiation pituitary hormone levels. ${ }^{87} \mathrm{~A}$ more recent review of stereotactic radiosurgery (SRS) for pituitary ablation showed an initial success rate of $87 \%$, when was defined as a greater than $50 \%$ reduction in pain ratings. ${ }^{97}$ Hypophysectomy for cancer pain control, particularly using SRS, is another example of a procedure that has largely been abandoned, but one that has some intriguing support in the literature. 


\section{Mesencephalotomy}

Stereotactic mesencephalotomy is a destructive procedure that disrupts the pain pathways (spinothalamic and trigeminothalamic tracts) at the midbrain level to treat medically refractory, nociceptive, contralateral cancer pain, particularly unilateral pain in the head and neck, in patients with a predicted longevity of 6 months or less. Although reported as a treatment for both cancer and neuropathic pain, ${ }^{3}$ recent results for noncancer pain have been disappointing. ${ }^{11}$ Its use has fallen out of favor, although the procedure may still have merit because it avoids complex neuromodulation procedures and may reduce the patient's dependency on opiate analgesics for pain control. ${ }^{45,55} \mathrm{~A}$ stereotactic lesion can be placed in the midbrain at the level of the inferior colliculus by direct MRI targeting, halfway between the lateral edge of the aqueduct and the lateral border of the midbrain, to disrupt the spinothalamic and trigeminothalamic pathways. ${ }^{45}$

\section{Cordotomy, Tractotomy, and Myelotomy}

We have recently reviewed the use of anterolateral cordotomy for cancer pain control. ${ }^{91}$ Historically, destructive procedures for cancer pain were the main form of neurosurgical pain treatment. As is the case for mesencephalotomy, the use of high-dose opioids for control of cancer pain has essentially replaced destructive procedures. However, as the limits of medical therapy to treat cancer pain are being increasingly recognized, particularly in regions with limited access to pain medications, the interest in destructive surgical techniques for pain control is growing.

In our review, we identified 47 papers that included 3601 patients treated by cordotomy. ${ }^{91}$ Many reported more than 200 patients, with follow-up exceeding 6 months. The most recent cordotomy literature originated outside the US where the economic environment fostered the readoption of ablation procedures..$^{50,89}$ Cordotomy in particular was the most extensively studied and reviewed procedure. Given the large number of patients studied, consistent results, and multiplicity of reports, cumulative evidence suggests that cordotomy may play an important role in the treatment of cancer pain, even though evidence quality for individual studies was relatively low.

Kanpolat et al. revolutionized the methods by which destructive spinal cord ablative procedures were performed and demonstrated higher safety and efficacy using image guidance. ${ }^{50}$ This surgical approach makes the implementation of cordotomy in the 21 st century much more accessible to a generation of neurosurgeons who are comfortable with image-guided surgery, but who have not yet been trained in this particular procedure. ${ }^{89}$ Other similar image-guided procedures can be performed in the lower brainstem and upper cervical spinal cord to disrupt the trigeminal tract and nucleus in cases of intractable trigeminal neuropathic pain (TNP). ${ }^{112}$ Midline myelotomy ${ }^{77}$ may also fall into the category of destructive spinal cord procedures that may be selectively used in patients with intractable pelvic pain due to malignancy, although the data for this procedure is very limited.

\section{Sympathectomy \\ Sympathectomy and related procedures (splanchni-}

cectomy, celiac plexus block) appear to have a potential role in reducing visceral pain, primarily from pancreatic cancer. ${ }^{4,10,25,28,71}$ A recent Cochrane analysis of the use of cervicothoracic or lumbar sympathectomy for neuropathic pain and complex regional pain syndrome (CRPS) concluded that the existing data are insufficient to support a recommendation with regard to sympathectomy for these pain conditions. ${ }^{104}$ There is essentially no modern neurosurgical literature on this topic, and procedures that appear to be effective are generally performed either by anesthesiologists (celiac plexus block), or either thoracic or general surgeons (splanchnicectomy, sympathectomy).

\section{Neuromodulation}

Neuromodulation currently occupies the lead position in the armamentarium of surgery for chronic pain. It is estimated that 34,000 spinal cord stimulation (SCS) procedures are performed annually worldwide. ${ }^{12}$ The current neuromodulatory approaches used for pain management are either pharmacological, utilizing intrathecal pumps to directly administer medications into the CSF space, or electrical, utilizing electrical stimulation to modulate various targets of the nervous system such as peripheral nerves, dorsal root ganglia, spinal cord, and brain. The main indication for neuromodulation is chronic pain not due to malignancy. The main neuromodulatory approach utilized for cancer-related pain is intrathecal opioids. The use of SCS in cancer-related pain is fairly limited, if it is used at all for this indication.

\section{Pharmacological Neuromodulation \\ Intrathecal Opiates}

Yaksh and Rudy demonstrated the efficacy of intrathecal opioids in alleviating pain in rats. ${ }^{121}$ This discovery opened the door for intrathecal opioid use, which temporally coincided with a period of more liberal use of oral opioids. Intrathecal use of opioids allows the use of highly potent doses with minimal systemic side effects. ${ }^{56,110}$ The most common use of intrathecal opioids in humans remains nociceptive pain due to cancer, or nociceptive pain due to "mechanical" spinal disorders. Despite demonstrated efficacy in animals, evidence that neuropathic pain responds to intrathecal opiates is limited. ${ }^{122}$ Axial back pain is more likely to respond favorably to intrathecal opioids than does neuropathic leg pain.

The chronic administration of opioids via the intrathecal space requires a pump with a reservoir that is powered by a micromotor. Currently, there are several commercial catheters and pumps, including programmable as well as constant rate pumps. The use of intrathecal opioids requires a trial phase much the same way as SCS. This trial period allows for identification of the effective intrathecal agent and the effective dose. Pump implantation is typically performed under general anesthesia but can be performed using local anesthesia, particularly in patients with tenuous medical conditions such as late-stage cancer. $\mathrm{Pa}-$ tients using intrathecal opioid administration devices need to have their pump reservoirs refilled at intervals related to concentration of medication used, reservoir capacity, and daily effective dose..$^{93}$ 
Nonopioid medications have also been used through the intrathecal route. These agents putatively avoid the issues of tolerance to opiates (which occurs with intrathecal use) and side effects of intrathecal opioids such as constipation, nausea, lethargy, pruritis, diaphoresis, mental status changes, urinary retention, and peripheral edema. ${ }^{5}$ Several agents have been used for intrathecal administration for pain, including clonidine, octreotide, ziconotide, $\mathrm{N}$-methyl-D-aspartate antagonists such as dextromethorphan, $\mathrm{MH}-801$, benzodiazepines, nitric oxide synthetase inhibitors, bioactive implants, tricyclic antidepressants, and liposomal encapsulation of local anesthetics and lidocaine. ${ }^{34}$ Of these, currently only clonidine and ziconotide are used with any frequency.

\section{Intracerebroventricular Opioids}

The use of intracerebroventricular opiates was originally reported by Leavens and colleagues ${ }^{61}$ based on earlier evidence that direct administration of opiates to the ventricle could produce analgesia. ${ }^{6}$ However, intracerebroventricular opiate administration is becoming increasingly rare and is now utilized almost exclusively for otherwise intractable end-stage cancer pain of the craniofacial region. ${ }^{86}$

\section{Electrical Neuromodulation}

\section{Spinal Cord Stimulation}

The use of SCS was introduced by Shealy et al. ${ }^{100}$ almost immediately following the publication of the gate theory of pain by Melzack and Wall in $1965{ }^{73}$ interestingly, its FDA approval was only obtained in 1989 for treatment of chronic pain. The mechanism of action of SCS remains incompletely understood, but SCS is known to suppress hyperexcitability of the wide dynamic range neurons in the dorsal horn ${ }^{18}$ and to lead to inhibition of other lamina III-IV in the dorsal horn. ${ }^{27}$

The first generations of SCS systems consisted of unipolar electrodes and a pulse generator/power source that was external and connected transcutaneously by induction through an antenna to the permanently implanted system. Although the original application of SCS was via electrodes implanted directly on the dorsal spinal cord, socalled dorsal column stimulation, problems with infection and CSF leakage with this method led to screening procedures using epidural stimulating electrodes. It was soon realized that epidural SCS produced effective pain relief, so dorsal column stimulation was abandoned. Frequencies of SCS were determined by the treating physician, or patient, based on effectiveness and comfort, and were typically in the range of tens of Hertz. Patients could control the amplitude of stimulation, which caused paresthesias, ideally overlapping the painful area. Trial stimulation was conducted over days to determine candidacy for a permanent implant.

Currently, epidural trial electrode positioning is performed in the operating room under local anesthesia to determine the optimal placement of the electrodes by producing paresthesia in the area of pain, avoiding untoward effects such as motor stimulation or sensory stimulation outside of the region of pain. Permanent electrode implan- tation can be performed under local or general anesthesia. ${ }^{33}$

Multiple studies of SCS have been performed to examine the short- and long-term efficacies of the therapy. To a large degree, the use of SCS for pain control was originally based on class III case series, although some prospective randomized trials have been conducted. ${ }^{60}$ While the bulk of the past evidence would not be acceptable by contemporary evidentiary standards, it suggested that SCS was effective and safe for the treatment of various types of pain. Neuropathic pain, in particular, remains its chief indication due to its intractability to other medical and surgical therapies, and its relative responsiveness to neurostimulation. Leg pain following lumbar spine surgery is currently the main indication for SCS. Axial back pain may also respond, but is less durable over the long term. More recent randomized controlled trials and systematic reviews have demonstrated more substantial evidence supporting the use of SCS for chronic neuropathic pain, particularly pain of spinal origin. ${ }^{37}$ CRPS, peripheral neuropathic pain, vascular insufficiency pain, and anginal pain are among the other types of pain that have responded to SCS. ${ }^{53,79}$

In the past few years, SCS has evolved by way of new targets, higher frequencies of stimulation, and innovative pulse waveforms and patterns. These developments have renewed interest in SCS, and have restored the discussion on targeting different types of pain with these new technologies. For example, the Senza HF10 trial suggested that high-frequency $10-\mathrm{Hz}$ SCS was superior to conventional lower-frequency SCS for control of pain due to failed back surgery syndrome, including back and leg pain with a stronger effect on back pain. These results continued to hold true at 24 months..$^{51,52}$ Other randomized controlled trials have not demonstrated the superiority of high-frequency over conventional SCS. ${ }^{20}$

De Ridder et al. ${ }^{21}$ has introduced the concept of "burst" spinal cord stimulation. The particular pattern used is 500$\mathrm{Hz}$ noncharge-balanced bursts nested in $40-\mathrm{Hz}$ cycles. Burst stimulation has been postulated to activate both the medial ("protopathic" or paleospinothalamic) as well as the lateral ("epicritic" or neospinothalamic) pain pathways with a particular effect on the affective (medial) pain pathways, as demonstrated by quantitative electroencephalography measurements and by profile of mood states assessment. ${ }^{21,22}$ The SUNBURST trial demonstrated superiority of burst spinal cord stimulation over conventional spinal cord stimulation for treatment of back and limb pain. ${ }^{23}$

DRG stimulation (DRGS) is another new addition to the spectrum of SCS. DRGS provides an alternative for stimulation for CRPS types 1 and 2 and conditions with peripheral nerve injury leading to neuropathic pain. The pivotal FDA trial of DRGS showed superiority of DRGS over SCS despite very good pain relief by SCS compared to previous SCS trials in CRPS (55\%). ${ }^{24}$ "Closed loop" SCS had been recently tested with promising results. The stimulation system maintains a therapeutic range that maximizes the recruitment of dorsal column neurons involved in pain processing by using evoked compound action potential as a biomarker that is measured continuously. ${ }^{98}$ 
Clearly SCS is going through a period of change and innovation. Whether these newer methods will or will not become fixtures in the therapy will be established over time by continued testing and outcomes analysis.

\section{Motor Cortex Stimulation}

Initially, motor cortex stimulation (MCS) was considered a solution to difficult central pain problems. Tsubokawa and his colleagues first introduced MCS for treatment of pain, after the realization that postcentral stimulation was ineffective and, in some instances, exacerbated the pain. ${ }^{114,115}$ MCS does appear to increase blood flow to the ipsilateral thalamus, cingulate gyrus, orbitofrontal cortex, insula, and brainstem..$^{35,36}$

Several pain syndromes have been treated by MCS, all variants of central pain syndromes such as thalamic pain and Wallenberg syndrome. TNP was one of the initial and most promising indications for MCS given the size of facial representation in the motor cortex. ${ }^{12}$ Unfortunately, MCS did not stand the test of time and has not been shown to be effective in the long term. Our group showed that MCS for neuropathic facial pain was only effective in $37.5 \%$ of patients with only a moderate treatment effect. ${ }^{94}$ Sachs and colleagues ${ }^{99}$ subsequently reported that only 1 of 14 patients experienced sustained meaningful relief from a variety of conditions, including TNP, poststroke pain, phantom limb pain, spinal cord arteriovenous malformation, brainstem cavernoma, and facial hemangiopericytoma. Additionally, MCS is not currently covered by insurance or Medicare in the US. This fact, and its lack of proven efficacy, has led to its virtual disappearance in US pain surgery practice.

\section{Deep Brain Stimulation}

Deep brain stimulation (DBS) for pain was the first application of multicontact stimulation electrode arrays, and preceded the main present use of DBS for movement disorder surgery. Pool reported the analgesic effect of septal stimulation during awake psychosurgery ${ }^{84}$ and subsequently Mazars et al..$^{2}$ reported the analgesic effect of thalamic stimulation. DBS for pain remained largely unexamined until the 1970s, when based on the phenomenon of "stimulus produced analgesia" in experimental animals, periaqueductal gray (PAG) and later periventricular gray (PVG) stimulation was applied to humans. ${ }^{43,44,95,96}$ Other targets for DBS were tried, and results were reported as small case series. The heterogeneity of targets, variations in indications for DBS for pain, and poor study designs resulted in an unconvincing argument for DBS for pain, one that would not stand up to current standards of evidence. This was further amplified by the small number of total patients treated. A prospective trial for DBS for pain was aborted due to lack of enrollment, and the FDA, then in its expanded role of regulating devices in addition to drugs, did not grant approval. ${ }^{17}$ DBS for pain is currently not generally a technology covered by insurance carriers or Medicare in the US.

Despite this history, investigators have continued to examine the potential of DBS for pain. One group has introduced the concept of combining thalamic stimulation and PAG/PVG in the same patient for poststroke pain. ${ }^{80}$
They have reported the long-term outcomes of DBS for neuropathic pain in 59 patients who either received PAG/ PVG stimulation, thalamic stimulation, or both. Thirtynine $(66 \%)$ of their 59 subjects demonstrated some benefit initially, and 15 patients demonstrated greater than $30 \%$ improvement in the visual analog scale, McGill pain questionnaire, SF-36, and EQ-5D at 42 months. ${ }^{7}$ Despite these seemingly encouraging results, these investigators went on to evaluate the efficacy of anterior cingulate cortex stimulation and showed results that were superior to thalamic and PAG/PVG stimulation for treatment of neuropathic pain. ${ }^{8,9}$

Cluster headache is a unique problem that had been treated with some preliminary success using hypothalamic stimulation. Initial case reports ${ }^{33,64}$ were promising, and these have been refined by analysis of optimized hypothalamic sites for stimulation. ${ }^{2}$ Thus far, hypothalamic DBS for cluster headache has not been subjected to a larger prospective series with appropriate controls, but probably warrants further study.

A more recent and well-designed randomized controlled trial for DBS of the ventral striatum/anterior limb of the internal capsule in patients with poststroke pain has been conducted. This study failed to achieve its primary outcome goal, which was $\geq 50 \%$ improvement of a pain/ disability index in 50\% of the patients with active DBS when compared to sham stimulation. However, they did note a significant difference in the affective sphere of pain with active ventral striatum/anterior limb of the internal capsule. ${ }^{63}$ While the ultimate future of DBS for pain remains in question, it is clear that it has no current evidencebased indication.

\section{Peripheral Nerve Stimulation}

Peripheral nerve stimulation (PNS) is a historic application of neurostimulation to treat chronic pain. As with much of neuromodulation, the evidence base for this technology is not very substantial. Of all PNS indications, perhaps occipital nerve stimulation (ONS) for "occipital neuralgia" is most common, ${ }^{120}$ with trigeminal nerve branch stimulation being a close second. ${ }^{48}$

The Congress of Neurological Surgeons has sponsored a guidelines document examining ONS for the treatment of medically refractory occipital neuralgia. There were 9 studies meeting the inclusion criteria and included in these guidelines. The systematic literature review concluded that at best, only a level III recommendation for ONS in the treatment of occipital neuralgia could be made, and therefore it is an "option." "105 Several studies have examined peripheral trigeminal nerve stimulation for trigeminal neuropathic pain with variable degrees of success. It is an option for TNP, particularly for V1 neuropathic pain. The use of ONS and peripheral trigeminal stimulation remain limited by the lack of evidence for long-term efficacy in well-designed studies. ${ }^{102,103}$

\section{Trigeminal Neuralgia}

The surgical treatment of TN holds a special place in the surgical management of pain. Primarily, this is due to the relative clarity of this diagnosis and the numerous 
effective medical and surgical therapies for this disorder. Diagnosis is the primary step in the management of facial pain. Fifteen years ago, one of us (K.J.B.) proposed a new classification for facial pain. ${ }^{13}$ This system has become an acceptable alternative to more complex classification schemes ${ }^{41}$ and has produced a significant body of outcomes research results.

It appears that higher-grade neurovascular compression (NVC) plays a major role in the development of TN, particularly in older patients. ${ }^{46,68}$ Although the literature suggests that the theoretical support for a vascular compressive etiology for TN is weak, the surgical outcome data are relatively convincing. ${ }^{111}$ It now appears that younger patients, particularly females, may develop classical type 1 TN (TN1) in the absence of any NVC. ${ }^{57}$ Contrary to neurological dictum, at the time of diagnosis these younger women do not have, nor do they go on to develop, multiple sclerosis. ${ }^{69}$ We believe that this entity, TN without NVC, may be a separate disorder requiring different modalities of surgical therapy. ${ }^{58}$ Preoperative imaging now plays a major role in the diagnosis and management of all patients with TN1 because the approach to surgery in TN patients with and without NVC are different. ${ }^{75}$

We have now demonstrated that the size of the posterior fossa seems to have a striking impact on the development of TN1 in males and females. ${ }^{40}$ We have also recently reported that knowledge of only two parameters prior to surgery, i.e., the diagnosis of TN1 and the grade of NVC (IIII), can accurately predict the pain-free outcome and durability of microvascular decompression postoperatively. ${ }^{39}$

In general, most pains that are the consequence of nervous system injury (peripheral or central) are not improved by further injury to the nervous system, and may, in fact, worsen. TN is, broadly speaking, a neuropathic pain, because it seems to derive from pathology in the trigeminal ganglion or retrogasserian root. In this sense, TN is unique in that it responds to ablative procedures such as peripheral neurectomy, RF rhizotomy, glycerol rhizolysis, balloon compression, retrogasserian internal neurolysis/ rhizotomy, and SRS. With the possible exception of DREZ lesions for deafferentation pain, TN may be the only major neuropathic pain that reliably responds favorably to a destructive procedure. Our suspicion is that damage to the afferent system simply interferes with the sensory stimulus that triggers the onset of TN, consistent with disruption of a fundamental feature of the "ignition hypothesis" for TN. ${ }^{88}$ Of note, some rarer conditions such as glossopharyngeal neuralgia and intermedius (geniculate) neuralgia may also respond well to destructive procedures. ${ }^{42,109}$

\section{The Future of Pain Surgery}

The future of pain surgery will be influenced by new technologies that promise not just palliation, but actual restoration. The following two cases will serve to exemplify this trend.

\section{Genomics and Gene Therapy}

Our hope is that a study of full genome sequencing in patients with TN1, currently underway, will yield an answer to the question of which genes predispose individuals to develop TN. Discovery in this area may lead to the identification of new, or possibly overlooked, pharmacological agents that will be effective for controlling TN with minimal side effects. TN may also represent the ideal target for gene therapy, since the primary sensory ganglion is percutaneously accessible, affording access for the introduction of attenuated viral vectors that can deliver and incorporate restorative genetic sequences, using CRISPR technology or other modalities, into the ganglionic somata.

\section{Dorsal Horn Restoration}

Over the past few decades, tissue transplantation for restoration of function in the nervous system has a long, and not very successful, history. However, a new generation of implants may be changing that record of failure. Basbaum and colleagues have now produced a series of reports demonstrating that spinal cord transplants of embryonic cortical GABAergic interneuron progenitors from the medial ganglionic eminence can overcome the mechanical hypersensitivity produced in different neuropathic pain models in adult mice. These medial ganglionic eminence cells integrate into the spinal cord circuitry and form GABA-A inhibitory synapses with the host, and prevent the development of nerve-injury induced mechanical hypersensitivity by synaptic release of GABA..$^{31,66}$ If these experimental results can be exported to humans, this will represent perhaps the first truly restorative treatment for neuropathic pain.

\section{Concluding Remarks}

Pain surgery, like much in the practice of neurological surgery, suffers from a relative lack of a strong evidence base. Acquiring this evidence continues to be the task at hand. Corporate sponsorship of outcomes research raises the issue of inherent bias, and while there are methods and strategies to eliminate bias in studies of implantable technologies, it is hard to imagine that a company will sponsor research that fundamentally threatens the viability of their products. In contrast, studies on ablative procedures have no obvious sponsors, other than NIH, other granting agencies, or private foundations. Grant support for clinical studies remains a challenge, albeit not an insurmountable one. Future investigators should take heart that small, wellconducted studies can make a large difference in practice.

Combining the efforts of multiple centers is one potential strategy that could mitigate the costs of pain surgery research on individual centers or investigators, and ultimately could improve study design. Tasker ${ }^{106}$ has aptly argued that meaningful comparisons between the work of different centers in the area of pain surgery will only be possible when the following guidelines of evidence-based practice are adopted: 1) all patients in the reported series have a uniform diagnosis; 2) all patients receive the same treatment; 3) other treatment modalities, particularly the use of narcotics, must be uniformly handled throughout the group; 4) preoperative and postoperative pain assessment must be performed on multiple occasions over a sufficiently long follow-up by disinterested and ideally blinded observers; and 5) when a particular therapy emerges as superior under such scrutiny, in then must be assessed 
in multiple centers to allow a consensus statement, such as that for modulatory surgery. Only when these criteria are met will we be sure of the relative efficacy of different treatments.

While Tasker's comments were originally directed at the interpretation of the published results of medial thalamotomy for pain, they represent the standard for the evaluation of the entirety of pain surgery. These exhortations, from someone whom many of us regard as the most highly respected functional neurosurgeon of our time, should be guideposts for our future explorations of novel surgical approaches to the treatment of pain.

\section{References}

1. Acar F, Miller J, Golshani KJ, Israel ZH, McCartney S, Burchiel KJ: Pain relief after cervical ganglionectomy (C2 and C3) for the treatment of medically intractable occipital neuralgia. Stereotact Funct Neurosurg 86:106-112, 2008

2. Akram H, Miller S, Lagrata S, Hariz M, Ashburner J, Behrens T, et al: Optimal deep brain stimulation site and target connectivity for chronic cluster headache. Neurology 89:2083-2091, 2017

3. Amano K, Kawamura H, Tanikawa T, Kawabatake H, Iseki H, Taira T: Stereotactic mesencephalotomy for pain relief. A plea for stereotactic surgery. Stereotact Funct Neurosurg 59:25-32, 1992

4. Amr YM, Makharita MY: Neurolytic sympathectomy in the management of cancer pain-time effect: a prospective, randomized multicenter study. J Pain Symptom Manage 48:944-956.e2, 2014

5. Anderson VC, Burchiel KJ: A prospective study of longterm intrathecal morphine in the management of chronic nonmalignant pain. Neurosurgery 44:289-301, 1999

6. Atweh SF, Kuhar MJ: Autoradiographic localization of opiate receptors in rat brain. II. The brain stem. Brain Res 129:1-12, 1977

7. Boccard SG, Pereira EA, Moir L, Aziz TZ, Green AL: Long-term outcomes of deep brain stimulation for neuropathic pain. Neurosurgery 72:221-231, 2013

8. Boccard SG, Pereira EA, Moir L, Van Hartevelt TJ, Kringelbach ML, FitzGerald JJ, et al: Deep brain stimulation of the anterior cingulate cortex: targeting the affective component of chronic pain. Neuroreport 25:83-88, 2014

9. Boccard SGJ, Prangnell SJ, Pycroft L, Cheeran B, Moir L, Pereira EAC, et al: Long-term results of deep brain stimulation of the anterior cingulate cortex for neuropathic pain. World Neurosurg 106:625-637, 2017

10. Bosanquet DC, Wilcox CR, Rasheed A: Bilateral thoracoscopic splanchnotomy to alleviate pain in chronic pancreatic disease. Ann Thorac Surg 101:e91-e93, 2016

11. Bosch DA: Stereotactic rostral mesencephalotomy in cancer pain and deafferentation pain. A series of 40 cases with follow-up results. J Neurosurg 75:747-751, 1991

12. Brown JA, Barbaro NM: Motor cortex stimulation for central and neuropathic pain: current status. Pain 104:431-435, 2003

13. Burchiel KJ: A new classification for facial pain. Neurosurgery 53:1164-1167, 2003

14. Burchiel KJ: Spontaneous impulse generation in normal and denervated dorsal root ganglia: sensitivity to alpha-adrenergic stimulation and hypoxia. Exp Neurol 85:257-272, 1984

15. Burchiel KJ, Johans TJ: Surgical management of chronic pain resulting from peripheral nerve injury. Perspect Neurol Surg 3:16-33, 1992

16. Cetas JS, Saedi T, Burchiel KJ: Destructive procedures for the treatment of nonmalignant pain: a structured literature review. J Neurosurg 109:389-404, 2008
17. Coffey RJ: Deep brain stimulation for chronic pain: results of two multicenter trials and a structured review. Pain Med 2:183-192, 2001

18. Coggeshall RE: Afferent fibers in the ventral root. Neurosurgery 4:443-448, 1979

19. Daunter AK, Kratz AL, Hurvitz EA: Long-term impact of childhood selective dorsal rhizotomy on pain, fatigue, and function: a case-control study. Dev Med Child Neurol 59:1089-1095, 2017

20. De Andres J, Monsalve-Dolz V, Fabregat-Cid G, Villanueva-Perez V, Harutyunyan A, Asensio-Samper JM, et al: Prospective, randomized blind effect-on-outcome study of conventional vs high-frequency spinal cord stimulation in patients with pain and disability due to failed back surgery syndrome. Pain Med 18:2401-2421, 2017

21. De Ridder D, Plazier M, Kamerling N, Menovsky T, Vanneste S: Burst spinal cord stimulation for limb and back pain. World Neurosurg 80:642-649, 649.e1, 2013

22. de Vos CC, Bom MJ, Vanneste S, Lenders MW, de Ridder D: Burst spinal cord stimulation evaluated in patients with failed back surgery syndrome and painful diabetic neuropathy. Neuromodulation 17:152-159, 2014

23. Deer T, Slavin KV, Amirdelfan K, North RB, Burton AW, Yearwood TL, et al: Success using neuromodulation with BURST (SUNBURST) study: results from a prospective, randomized controlled trial using a novel burst waveform. Neuromodulation 21:56-66, 2018

24. Deer TR, Levy RM, Kramer J, Poree L, Amirdelfan K, Grigsby E, et al: Dorsal root ganglion stimulation yielded higher treatment success rate for complex regional pain syndrome and causalgia at 3 and 12 months: a randomized comparative trial. Pain 158:669-681, 2017

25. Dobosz Ł, Kaczor M, Stefaniak TJ: Pain in pancreatic cancer: review of medical and surgical remedies. ANZ J Surg 86:756-761, 2016

26. Domeshek LF, Krauss EM, Snyder-Warwick AK, LauridoSoto O, Hasak JM, Skolnick GB, et al: Surgical Treatment of neuromas improves patient-reported pain, depression, and quality of life. Plast Reconstr Surg 139:407-418, 2017

27. Dubuisson D: Effect of dorsal-column stimulation on gelatinosa and marginal neurons of cat spinal cord. J Neurosurg 70:257-265, 1989

28. Eisenberg E, Carr DB, Chalmers TC: Neurolytic celiac plexus block for treatment of cancer pain: a meta-analysis. Anesth Analg 80:290-295, 1995

29. Emery E, Blondet E, Mertens P, Sindou M: Microsurgical DREZotomy for pain due to brachial plexus avulsion: longterm results in a series of 37 patients. Stereotact Funct Neurosurg 68:155-160, 1997

30. Engel A, Rappard G, King W, Kennedy DJ: The effectiveness and risks of fluoroscopically-guided cervical medial branch thermal radiofrequency neurotomy: a systematic review with comprehensive analysis of the published data. Pain Med 17:658-669, 2016

31. Etlin A, Bráz JM, Kuhn JA, Wang X, Hamel KA, Llewellyn-Smith IJ, et al: Functional synaptic integration of forebrain GABAergic precursors into the adult spinal cord. J Neurosci 36:11634-11645, 2016

32. Falco FJ, Manchikanti L, Datta S, Wargo BW, Geffert S, Bryce DA, et al: Systematic review of the therapeutic effectiveness of cervical facet joint interventions: an update. Pain Physician 15:E839-E868, 2012

33. Franzini A, Ferroli P, Leone M, Bussone G, Broggi G: Hypothalamic deep brain stimulation for the treatment of chronic cluster headaches: a series report. Neuromodulation 7:1-8, 2004

34. Garber JE, Hassenbusch SJ: Innovative intrathecal analgesics, in Burchiel K (ed): Surgical Management of Pain. New York: Thieme, 2002, pp 948-957 
35. García-Larrea L, Peyron R, Mertens P, Grégoire MC, Lavenne F, Bonnefoi F, et al: Positron emission tomography during motor cortex stimulation for pain control. Stereotact Funct Neurosurg 68:141-148, 1997

36. García-Larrea L, Peyron R, Mertens P, Gregoire MC, Lavenne F, Le Bars D, et al: Electrical stimulation of motor cortex for pain control: a combined PET-scan and electrophysiological study. Pain 83:259-273, 1999

37. Grider JS, Manchikanti L, Carayannopoulos A, Sharma ML, Balog CC, Harned ME, et al: Effectiveness of spinal cord stimulation in chronic spinal pain: a systematic review. Pain Physician 19:E33-E54, 2016

38. Guse DM, Moran SL: Outcomes of the surgical treatment of peripheral neuromas of the hand and forearm: a 25-year comparative outcome study. Ann Plast Surg 71:654-658, 2013

39. Hardaway FA, Gustafsson HC, Holste K, Burchiel KJ, Raslan AM: A novel scoring system as a preoperative predictor for pain-free survival after microsurgery for trigeminal neuralgia. J Neurosurg [epub ahead of print January 25 , 2019. DOI: $10.3171 / 2018.9$.JNS181208]

40. Hardaway FA, Holste K, Ozturk GO, Pettersson D, Pollock JM, Burchiel KJ, et al: Sex-dependent posterior fossa anatomical differences in trigeminal neuralgia patients with and without neurovascular compression: a volumetric MRI age- and sex-matched case-control study. J Neurosurg [in press], 2018

41. Headache Classification Committee of the International Headache Society (IHS): The International Classification of Headache Disorders, 3rd edition (beta version). Cephalalgia 33:629-808, 2013

42. Holste KG, Hardaway FA, Raslan AM, Burchiel KJ: Painfree and pain-controlled survival after sectioning the nervus intermedius in nervus intermedius neuralgia: a single-institution review. J Neurosurg [epub ahead of print August 17, 2018. DOI: $10.3171 / 2018.3 . J N S 172495]$

43. Hosobuchi Y, Adams JE, Linchitz R: Pain relief by electrical stimulation of the central gray matter in humans and its reversal by naloxone. Science 197:183-186, 1977

44. Hosobuchi Y, Adams JE, Rutkin B: Chronic thalamic stimulation for the control of facial anesthesia dolorosa. Arch Neurol 29:158-161, 1973

45. Ivanishvili Z, Pujara S, Honey CM, Chang S, Honey CR: Stereotactic mesencephalotomy for palliative care pain control: a case report, literature review and plea to rediscover this operation. Br J Neurosurg 30:444-447, 2016

46. Jannetta PJ: Arterial compression of the trigeminal nerve at the pons in patients with trigeminal neuralgia. J Neurosurg 26: $159-162,162,1967$

47. Jeanmonod D, Werner B, Morel A, Michels L, Zadicario E, Schiff G, et al: Transcranial magnetic resonance imagingguided focused ultrasound: noninvasive central lateral thalamotomy for chronic neuropathic pain. Neurosurg Focus 32(1): E1, 2012

48. Johnson MD, Burchiel KJ: Peripheral stimulation for treatment of trigeminal postherpetic neuralgia and trigeminal posttraumatic neuropathic pain: a pilot study. Neurosurgery 55:135-142, 2004

49. Kanpolat Y, Tuna H, Bozkurt M, Elhan AH: Spinal and nucleus caudalis dorsal root entry zone operations for chronic pain. Neurosurgery 62 (3 Suppl 1):235-244, 2008

50. Kanpolat Y, Ugur HC, Ayten M, Elhan AH: Computed tomography-guided percutaneous cordotomy for intractable pain in malignancy. Neurosurgery 64 (3 Suppl):ons 187ons 194, 2009

51. Kapural L, Yu C, Doust MW, Gliner BE, Vallejo R, Sitzman BT, et al: Comparison of 10-kHz high-frequency and traditional low-frequency spinal cord stimulation for the treatment of chronic back and leg pain: 24-month results from a multicenter, randomized, controlled pivotal trial. Neurosurgery 79:667-677, 2016

52. Kapural L, Yu C, Doust MW, Gliner BE, Vallejo R, Sitzman BT, et al: Novel 10-kHz High-frequency therapy (HF10 therapy) is superior to traditional low-frequency spinal cord stimulation for the treatment of chronic back and leg pain: the SENZA-RCT randomized controlled trial. Anesthesiology 123:851-860, 2015

53. Kemler MA, Barendse GAM, van Kleef M, de Vet HCW, Rijks CPM, Furnée CA, et al: Spinal cord stimulation in patients with chronic reflex sympathetic dystrophy. $\mathbf{N}$ Engl J Med 343:618-624, 2000

54. Khan FR, Henderson JM: Does ganglionectomy still have a role in the era of neuromodulation? World Neurosurg 77:280-282, 2012

55. Kim DR, Lee SW, Son BC: Stereotactic mesencephalotomy for cancer-related facial pain. J Korean Neurosurg Soc 56:71-74, 2014

56. Kleinmann B, Wolter T: Intrathecal opioid therapy for non-malignant chronic pain: a long-term perspective. Neuromodulation 20:719-726, 2017

57. Ko AL, Lee A, Raslan AM, Ozpinar A, McCartney S, Burchiel KJ: Trigeminal neuralgia without neurovascular compression presents earlier than trigeminal neuralgia with neurovascular compression. J Neurosurg 123:1519-1527, 2015

58. Ko AL, Ozpinar A, Lee A, Raslan AM, McCartney S, Burchiel KJ: Long-term efficacy and safety of internal neurolysis for trigeminal neuralgia without neurovascular compression. J Neurosurg 122: 1048-1057, 2015

59. Ko AL, Ozpinar A, Raskin JS, Magill ST, Raslan AM, Burchiel KJ: Correlation of preoperative MRI with the longterm outcomes of dorsal root entry zone lesioning for brachial plexus avulsion pain. J Neurosurg 124:1470-1478, 2016

60. Kumar K, Taylor RS, Jacques L, Eldabe S, Meglio M, Molet J, et al: Spinal cord stimulation versus conventional medical management for neuropathic pain: a multicentre randomised controlled trial in patients with failed back surgery syndrome. Pain 132:179-188, 2007

61. Leavens ME, Hill CS Jr, Cech DA, Weyland JB, Weston JS: Intrathecal and intraventricular morphine for pain in cancer patients: initial study. J Neurosurg 56:241-245, 1982

62. Lee $\mathrm{CH}$, Chung $\mathrm{CK}$, Kim CH: The efficacy of conventional radiofrequency denervation in patients with chronic low back pain originating from the facet joints: a meta-analysis of randomized controlled trials. Spine J 17:1770-1780, 2017

63. Lempka SF, Malone DA Jr, Hu B, Baker KB, Wyant A, Ozinga JG IV, et al: Randomized clinical trial of deep brain stimulation for poststroke pain. Ann Neurol 81:653-663, 2017

64. Leone M, Franzini A, Bussone G: Stereotactic stimulation of posterior hypothalamic gray matter in a patient with intractable cluster headache. N Engl J Med 345:14281429,2001

65. Lipinski LJ, Spinner RJ: Neurolysis, neurectomy, and nerve repair/reconstruction for chronic pain. Neurosurg Clin $\mathbf{N}$ Am 25:777-787, 2014

66. Llewellyn-Smith IJ, Basbaum AI, Bráz JM: Long-term, dynamic synaptic reorganization after GABAergic precursor cell transplantation into adult mouse spinal cord. J Comp Neurol 526:480-495, 2018

67. Loeser JD: Dorsal rhizotomy for the relief of chronic pain. J Neurosurg 36:745-750, 1972

68. Maarbjerg S, Wolfram F, Gozalov A, Olesen J, Bendtsen L: Significance of neurovascular contact in classical trigeminal neuralgia. Brain 138:311-319, 2015 
69. Magown P, Ko A, Burchiel KJ: The spectrum of trigeminal neuralgia without neurovascular compression. Neurosurgery [in press], 2018

70. Manchikanti L, Datta S, Gupta S, Munglani R, Bryce DA, Ward SP, et al: A critical review of the American Pain Society clinical practice guidelines for interventional techniques: part 2. Therapeutic interventions. Pain Physician 13:E215-E264, 2010

71. Masuda T, Kuramoto M, Shimada S, Ikeshima S, Yamamoto K, Nakamura K, et al: Splanchnicectomy for pancreatic cancer pain. BioMed Res Int 2014:941726, 2014

72. Mazars G, Roge R, Mazars Y: [Results of the stimulation of the spinothalamic fasciculus and their bearing on the physiopathology of pain.] Rev Neurol (Paris) 103:136-138, 1960 (Fr)

73. Melzack R, Wall PD: Pain mechanisms: a new theory. Science 150:971-979, 1965

74. Menon JP: Intracranial ablative procedures for the treatment of chronic pain. Neurosurg Clin N Am 25:663-670, 2014

75. Miller JP, Acar F, Hamilton BE, Burchiel KJ: Radiographic evaluation of trigeminal neurovascular compression in patients with and without trigeminal neuralgia. J Neurosurg 110:627-632, 2009

76. Moore AM, Bjurstrom MF, Hiatt JR, Amid PK, Chen DC: Efficacy of retroperitoneal triple neurectomy for refractory neuropathic inguinodynia. Am J Surg 212:1126-1132, 2016

77. Nauta HJW, Soukup VM, Fabian RH, Lin JT, Grady JJ, Williams CGA, et al: Punctate midline myelotomy for the relief of visceral cancer pain. J Neurosurg 92 (2 Suppl):125-130, 2000

78. North RB, Kidd DH, Campbell JN, Long DM: Dorsal root ganglionectomy for failed back surgery syndrome: a 5-year follow-up study. J Neurosurg 74:236-242, 1991

79. North RB, Kidd DH, Farrokhi F, Piantadosi SA: Spinal cord stimulation versus repeated lumbosacral spine surgery for chronic pain: a randomized, controlled trial. Neurosurgery 56:98-107, 2005

80. Owen SLF, Green AL, Stein JF, Aziz TZ: Deep brain stimulation for the alleviation of post-stroke neuropathic pain. Pain 120:202-206, 2006

81. Park TS, Edwards C, Liu JL, Walter DM, Dobbs MB: Beneficial effects of childhood selective dorsal rhizotomy in adulthood. Cureus 9:e1077, 2017

82. Park TS, Liu JL, Edwards C, Walter DM, Dobbs MB: Functional outcomes of childhood selective dorsal rhizotomy 20 to 28 years later. Cureus 9:e1256, 2017

83. Pisapia JM, Bhowmick DA, Farber RE, Zager EL: Salvage $\mathrm{C} 2$ ganglionectomy after $\mathrm{C} 2$ nerve root decompression provides similar pain relief as a single surgical procedure for intractable occipital neuralgia. World Neurosurg 77:362369, 2012

84. Pool JL: Psychosurgery in older people. J Am Geriatr Soc 2:456-466, 1954

85. Pope JE, Deer TR, Kramer J: A systematic review: current and future directions of dorsal root ganglion therapeutics to treat chronic pain. Pain Med 14:1477-1496, 2013

86. Raffa RB, Pergolizzi JV Jr: Intracerebroventricular opioids for intractable pain. Br J Clin Pharmacol 74:34-41, 2012

87. Ramirez LF, Levin AB: Pain relief after hypophysectomy. Neurosurgery 14:499-504, 1984

88. Rappaport ZH, Devor M: Trigeminal neuralgia: the role of self-sustaining discharge in the trigeminal ganglion. Pain 56: $127-138,1994$

89. Raslan AM: Percutaneous computed tomography-guided radiofrequency ablation of upper spinal cord pain pathways for cancer-related pain. Neurosurgery 62 (3 Suppl 1):226234, 2008

90. Raslan AM, Burchiel KJ: Neurosurgical advances in cancer pain management. Curr Pain Headache Rep 14:477-482, 2010

91. Raslan AM, Cetas JS, McCartney S, Burchiel KJ: Destructive procedures for control of cancer pain: the case for cordotomy. J Neurosurg 114:155-170, 2011

92. Raslan AM, McCartney S, Burchiel KJ: Management of chronic severe pain: cerebral neuromodulatory and neuroablative approaches. Acta Neurochir Suppl 97 (Pt 2):17-26, 2007

93. Raslan AM, McCartney S, Burchiel KJ: Management of chronic severe pain: spinal neuromodulatory and neuroablative approaches. Acta Neurochir Suppl 97 (Pt 1):33-41, 2007

94. Raslan AM, Nasseri M, Bahgat D, Abdu E, Burchiel KJ: Motor cortex stimulation for trigeminal neuropathic or deafferentation pain: an institutional case series experience. Stereotact Funct Neurosurg 89:83-88, 2011

95. Richardson DE, Akil H: Pain reduction by electrical brain stimulation in man. Part 1: Acute administration in periaqueductal and periventricular sites. J Neurosurg 47:178183,1977

96. Richardson DE, Akil H: Pain reduction by electrical brain stimulation in man. Part 2: Chronic self-administration in the periventricular gray matter. J Neurosurg 47:184-194, 1977

97. Roberts DG, Pouratian N: Stereotactic radiosurgery for the treatment of chronic intractable pain: a systematic review. Oper Neurosurg (Hagerstown) 13:543-551, 2017

98. Russo M, Cousins MJ, Brooker C, Taylor N, Boesel T, Sullivan R, et al: Effective relief of pain and associated symptoms with closed-loop spinal cord stimulation system: preliminary results of the Avalon Study. Neuromodulation 21:38-47, 2018

99. Sachs AJ, Babu H, Su YF, Miller KJ, Henderson JM: Lack of efficacy of motor cortex stimulation for the treatment of neuropathic pain in 14 patients. Neuromodulation 17:303311,2014

100. Shealy CN, Mortimer JT, Reswick JB: Electrical inhibition of pain by stimulation of the dorsal columns: preliminary clinical report. Anesth Analg 46:489-491, 1967

101. Sindou M: Study of the dorsal root entry zone: implications for pain surgery [thesis]. Lyon: University Of Lyon Press, 1972

102. Slavin KV: Peripheral nerve stimulation for neuropathic pain. Neurotherapeutics 5:100-106, 2008

103. Stidd DA, Wuollet AL, Bowden K, Price T, Patwardhan A, Barker S, et al: Peripheral nerve stimulation for trigeminal neuropathic pain. Pain Physician 15:27-33, 2012

104. Straube S, Derry S, Moore RA, Cole P: Cervico-thoracic or lumbar sympathectomy for neuropathic pain and complex regional pain syndrome. Cochrane Database Syst Rev (9):CD002918, 2013

105. Sweet JA, Mitchell LS, Narouze S, Sharan AD, Falowski SM, Schwalb JM, et al: Occipital nerve stimulation for the treatment of patients with medically refractory occipital neuralgia: Congress of Neurological Surgeons systematic review and evidence-based guideline. Neurosurgery 77:332-341, 2015

106. Tasker RR: Stereotactic medial thalamotomy for chronic pain: Is it an effective procedure?, in Burchiel KJ (ed): Surgical Management of Pain. New York: Thieme, 2002, pp 805-811

107. Taub A, Robinson F, Taub E: Dorsal root ganglionectomy for intractable monoradicular sciatica. A series of 61 patients. Stereotact Funct Neurosurg 65:106-110, 1995

108. Tedroff K, Löwing K, Åström E: A prospective cohort study investigating gross motor function, pain, and health-related quality of life 17 years after selective dorsal rhizotomy in cerebral palsy. Dev Med Child Neurol 57:484-490, 2015 
109. Teton ZE, Holste KG, Hardaway FA, Burchiel KJ, Raslan AM: Pain-free survival after vagoglossopharyngeal complex sectioning with or without microvascular decompression in glossopharyngeal neuralgia. J Neurosurg [epub ahead of print January 11, 2019. DOI: 10.3171/2018.8.JNS18239]

110. Textor LH: CE: Intrathecal pumps for managing cancer pain. Am J Nurs 116:36-44, 2016

111. Thomas KL, Vilensky JA: The anatomy of vascular compression in trigeminal neuralgia. Clin Anat 27:89-93, 2014

112. Thompson EM, Burchiel KJ, Raslan AM: Percutaneous trigeminal tractotomy-nucleotomy with use of intraoperative computed tomography and general anesthesia: report of 2 cases. Neurosurg Focus 35(3):E5, 2013

113. Thomson SM: Spinal cord stimulation: its role in managing chronic disease symptoms. Neuromodulation.com (https:// www.neuromodulation.com/assets/documents/Fact_Sheets/ fact_sheet_spinal_cord_stimulation.pdf) [Accessed January $8,2019]$

114. Tsubokawa T, Katayama Y, Yamamoto T, Hirayama T, Koyama S: Chronic motor cortex stimulation for the treatment of central pain. Acta Neurochir Suppl (Wien) 52:137-139, 1991

115. Tsubokawa T, Katayama Y, Yamamoto T, Hirayama T, Koyama S: Chronic motor cortex stimulation in patients with thalamic pain. J Neurosurg 78:393-401, 1993

116. Viswanathan A, Harsh V, Pereira EA, Aziz TZ: Cingulotomy for medically refractory cancer pain. Neurosurg Focus 35(3):E1, 2013

117. Wall PD, Devor M: Sensory afferent impulses originate from dorsal root ganglia as well as from the periphery in normal and nerve injured rats. Pain 17:321-339, 1983

118. Wallin J, Fiskå A, Tjølsen A, Linderoth B, Hole K: Spinal cord stimulation inhibits long-term potentiation of spinal wide dynamic range neurons. Brain Res 973:39-43, 2003
119. Weigel R, Capelle HH, Schmelz M, Krauss JK: Selective thoracic ganglionectomy for the treatment of segmental neuropathic pain. Eur J Pain 16:1398-1402, 2012

120. Weiner RL, Reed KL: Peripheral neurostimulation for control of intractable occipital neuralgia. Neuromodulation 2:217-221, 1999

121. Yaksh TL, Rudy TA: Analgesia mediated by a direct spinal action of narcotics. Science 192:1357-1358, 1976

122. Zacest A, Anderson VC, Burchiel KJ: The glass half empty or half full-how effective are long-term intrathecal opioids in post-herpetic neuralgia? A case series and review of the literature. Neuromodulation 12:219-223, 2009

123. Zacest AC, Magill ST, Anderson VC, Burchiel KJ: Longterm outcome following ilioinguinal neurectomy for chronic pain. J Neurosurg 112:784-789, 2010

\section{Disclosures}

Dr. Raslan reports a consultant relationship with Abbott.

\section{Author Contributions}

Conception and design: Burchiel. Acquisition of data: Burchiel. Analysis and interpretation of data: Burchiel. Drafting the article: both authors. Critically revising the article: both authors. Reviewed submitted version of manuscript: both authors. Approved the final version of the manuscript on behalf of both authors: Burchiel. Administrative/technical/material support: Burchiel.

\section{Correspondence}

Kim J. Burchiel: Oregon Health \& Science University, Portland, OR.burchiek@ohsu.edu. 